\title{
Managing anticoagulation in the COVID-19 era between lockdown and reopening phases
}

\author{
Daniela Poli ${ }^{1}$ - Alberto Tosetto $^{2} \cdot$ Gulatiero Palareti $^{3} \cdot$ Doris Barcellona $^{4} \cdot$ Antonio Ciampa $^{5} \cdot$ Elvira Grandone $^{6,7}$. \\ Cesare Manotti ${ }^{8}$. Marco Moia ${ }^{9}$. Alessandro Squizzato ${ }^{10}$. Vincenzo Toschi ${ }^{11}$. Sophie Testa ${ }^{12}$. On the behalf of Italian \\ Federation of Anticoagulation Clinics (FCSA)
}

Received: 11 May 2020 / Accepted: 29 May 2020 / Published online: 8 June 2020

(c) The Author(s) 2020

\begin{abstract}
Patients on anticoagulant treatment are constantly increasing, with an estimated prevalence in Italy of $2 \%$ of the total population. The recent spreadout of the COVID-19 pandemic requires a re-organization of Anticoagulation Clinics to prevent person-to-person viral diffusion and continue to offer the highest possible quality of assistance to patients. In this paper, based on the Italian Federation of Anticoagulation Clinics statements, we offer some advice aimed at improving patient care during COVID-19 pandemic, with particular regard to the lockdown and reopening periods. We give practical guidance regarding the following points: (1) re-thinking the AC organization, (2) managing patients on anticoagulants when they become infected by the virus, (3) managing anticoagulation surveillance in non-infected patients during the lockdown period, and (4) organizing the activities during the reopening phases.
\end{abstract}

Keywords Oral anticoagulants $\cdot$ Warfarin $\cdot$ DOAC $\cdot$ COVID-19 $\cdot$ Pandemic

\section{Introduction}

Patients on anticoagulant treatment are constantly increasing, with a prevalence of nearly $2 \%$ of the total population [1].

Anticoagulation Clinics (ACs) routinely manage thousands of patients taking anticoagulants, either vitamin $\mathrm{K}$ antagonists (VKAs), direct oral anticoagulants (DOACs), or

Daniela Poli

polida@aou-careggi.toscana.it

1 Dipartimento Cardiotoracovascolare, Centro Trombosi, Azienda Ospedaliero-Universitaria Careggi, Florence, Italy

2 UOS Centro Malattie Emorragiche e Trombotiche Divisione di Ematologia, Ospedale S. Bortolo, Vicenza, Italy

3 Fondazione Arianna Anticoagulazione, Bologna, Italy

4 Dipartimento di Scienze Mediche e Sanità Pubblica, Università di Cagliari, Cagliari, Italy

5 Centro Emostasi, AORN S.G. Moscati, Avellino, Italy

6 Thrombosis and Haemostasis Unit, Fondazione IRCCS "Casa Sollievo della Sofferenza”, San Giovanni Rotondo, Italy

7 Ob/Gyn Department of The First I.M. Sechenov Moscow State Medical University, Moscow, Russia parenteral drugs. ACs are pivotal in anticoagulation management, providing site visits for patients, remote monitoring, and integration with local health facilities [2].The recent spreadout of the COVID-19 pandemic requires a re-organization also of ACs, to prevent person-to-person diffusion. As most of the patients taking oral anticoagulants show at least one comorbid condition, it is becoming more evident that the ACs should continue to offer the highest possible quality of

8 Centro Emostasi, Medicina Interna ad indirizzo angiologico e coagulativo, Dipartimento di Medicina Interna e Specialistica, Azienda Ospedaliero-Universitaria di Parma, Parma, Italy

9 IRCCS MultiMedica Group, Milan, Italy

10 Department of Medicine and Surgery, Research Centre on Thromboembolic Diseases and Antithrombotic Therapies, University of Insubria, Varese and Como, Italy

11 Department of Hematology and Blood Transfusion, ASST Santi Paolo e Carlo, Milan, Italy

12 Centro Emostasi e Trombosi, Ospedale di Cremona, Cremona, Italy 
assistance, while assuring all safety standards against viral transmission.

In this paper, based on the Italian Federation of Anticoagulation Clinics (FCSA) statements, we offer some advice aimed at improving patient care during COVID-19 pandemic, with particular regard to the lockdown and reopening periods. We give practical guidance regarding the following points (Table 1):

1. Re-thinking the AC organization.

2. Managing patients on anticoagulants when they become infected by the virus.

3. Managing anticoagulation surveillance in non-infected patients during the lockdown period.

4. Organizing the activities during the reopening phases.

\section{Re-thinking the AC organization}

During pandemic periods and social distancing, all nonurgent health activities, such as periodical control visits in patients with chronic diseases or elective surgery, have been interrupted. Due to the necessity to maintain periodic controls in all anticoagulated patients, we suggests the following:

1. The AC ambulatory service should remain open. The staff (physicians, nurses, and administrative personnel) should routinely wear surgical masks and perform frequently hand hygiene.

2. Access to the AC should be verified and redesigned if necessary. Each patient must wear masks and wash hands with hydroalcoholic solutions before accessing the AC. Also, patients should be checked for fever and exposure to potential COVID-19 cases. Patients with possible exposure to COVID-19 cases or with body temperature $>37.5{ }^{\circ} \mathrm{C}$ should not be allowed to enter the center and immediately referred to the COVID-19 fast-track service [3].

3. Only the patient, except for a single caregiver in very special clinical situation (cognitive or motor limitations), should access the AC. Allowance for at least $1.5 \mathrm{~m}$ between patients should be provided in the waiting room.

4. For those patients on VKAs, the use of portable monitors to check PT INR should be recommended and rapid training performed.

5. All patients treated with either VKAs, DOACs, or heparin should be informed to keep at home adequate drug supplies (nearly 3 months).

6. Direct, accessible communication channels should be made available to the patients and/or their caregivers (e.g., by phone calls or e-mail).
7. Information material should be made available, aiming to address ordinary difficulties in the routine management of the treatment (e.g., minor bleedings and drugdrug interactions).

\section{Managing patients on anticoagulants when they become infected by the virus}

\section{Asymptomatic or paucisymptomatic patients}

Many COVID-19 patients may be treated and discharged to home. For these patients, continuing the usual treatment dose should be recommended, conditional that the patient is able to maintain adequate hydration and does not need to use of interfering drugs (see below). VKAs' treatment should be continued in patients with mechanical heart valves when a careful INR control is achievable.

\section{Symptomatic patients with moderate-to-severe disease}

If the clinical conditions deteriorate, several potentially important issues may cohesist. First, the concomitant use of interfering drugs may be necessary For instance, lopinavir/ritonavir may have the potential for $\mathrm{CYP} 2 \mathrm{C} 9 /$ CYP3A4 induction, as well as for P-gp inhibition $[4,5]$. Second, a severe coagulopathy has been widely described $[6,7]$. Prolonged prothrombin time is frequently reported, making difficult the monitoring of anticoagulation with PT-INR. Third, adequate oral food intake may be impossible in these patients with unpredictable effects on the absorption of drugs. We suggest withholding oral anticoagulation with either DOACs or VKAs and start antithrombotic treatment at therapeutic dose with lowmolecular-weight heparin (LMWH) in these patients. In patients with severely reduced renal function (estimated glomerular filtration rate $15-30 \mathrm{~mL} / \mathrm{min}$ ), we recommend measuring anti-Xa activity to maintain the therapeutic range $(\mathrm{aXa}=0.5-1.2 \mathrm{UI} / \mathrm{mL})$. In case of $\mathrm{CrCL}<15 \mathrm{~mL} /$ min, we recommend switching to unfractioned heparin (UFH) with a target aPTT ratio of $1.5-2.0$ or aXa activity 0.3-0.7 UI/mL [8].

\section{Manage anticoagulation surveillance in non-infected patients during the lockdown period}

In this phase, the vast majority of patients are afraid of getting infected and may have difficulties in reaching the AC. Moreover, the AC should provide a support to patient with counseling through phone calls and e-mail and to physicians 
directly involved in the management of COVID-19 patients for optimal antithrombotic strategy.

\section{Patients on VKAs}

All therapeutic prescriptions should be re-considered to reduce as much as possible the number of INR controls. All patients with stable anticoagulation should receive written prescriptions for longer intervals, possibly $6-8$ weeks $[9$, 10]. When longer intervals between laboratory controls are requested, patients should have easy access to telephone call with the doctors of $\mathrm{AC}$, if new clinical problems occur.

\section{Patients on DOACs}

Routine control visits for patients on DOACs should be delayed, providing telephone contact to evaluate the patient's clinical conditions and to identify selected patients who need a more careful surveillance.

\section{Organizing the activities during the reopening phases}

Currently, the evolution of the COVID-19 pandemic is still unknown. Italy, like many other European countries and the US, are experiencing the reopening phases of real-world activities, but recurrences of COVID-19 infections are expected. In this phase, we recommend that all ACs actively follow up anticoagulated patients through laboratory and clinical controls.

\section{General measures}

ACs should evaluate protocols and strategies to implement telemedicine services to reduce physical contacts in the case of COVID-19 recurrences. Clinical and laboratory control should be performed in all patients and the anamnesis updated, paying particular attention to recent co-morbidities and new therapies. All centers are invited to actively participate in drafting hospital protocols, collaborating with all the staff involved in the management of COVID-19 patients.

\section{Patients on VKAs}

PT INR should be checked as soon as possible. In these periods, the switch from VKAs should promptly be considered, in the absence of contraindication, in all patients.

\section{Scientific research}

All AC should participate in scientific studies that are now approved by National Ethical Committee and ongoing in our country on this new devastating disease. FCSA is always involved in scientific research and is now promoting the national START-COVID-19 registry within the frame of the wider START2-REGISTER study (ClinicalTrials.gov Identifier NCT02219984). All ACs, which are involved in the treatment of COVID-19 patients or are connected with COVID19-dedicated hospital units, are invited to take active part in the START-COVID-19 registry (online information available).

Table 1 Managing Anticoagulation Clinics during COVID-19 pandemic: suggested actions

\begin{tabular}{ll}
\hline & Actions \\
\hline The AC organization & The centers should remain open \\
& Act as hospital consultant in the management of COVID-19 anticoagulated patients. \\
& Assure protective devices available \\
& Measure body temperature before staff and patients enter into the clinic \\
& Personnel and patients must wear masks and wash hands with hydroalcoholic solutions \\
& Organize a strict appointments agenda \\
& Favor the use of portable monitors \\
& Patients should have home drug supplies for a long time (nearly 3 months) \\
& Facilitate PT INR controls in home patients, through nurses and patient's association \\
& Improve communications between patients and AC doctors through phone calls and/or e mail \\
Management of patients on anticoagu- & In hospitalized patient or in patients treated with antiviral drugs switch from oral to parenteral antico- \\
lants with COVID-19 infection & agulants \\
During the lockdown period & Re-consider the prolongation of INR controls between 4 and 8 weeks \\
& Favor telemedicine services \\
During the reopening phases & For patients on DOAC delay visits providing telephone or email contacts \\
& Strictly maintain all precautions recommended for ensure security for staff and patients \\
& Rapidly active clinical and laboratory control for all patients \\
In all phases & For AVK patients: organize PT-INR control for patients not reached during the lockdown phase \\
\hline & Switch from AVK to DOAC if possible \\
& Participate to local and national researches
\end{tabular}




\section{Compliance with ethical standards}

Conflicts of interest The authors declare that they have no conflict of interest.

Statement of human and animal rights This article does not contain any studies with human participants or animals performed by any of the authors.

Informed consent Informed consent was not required.

Open Access This article is licensed under a Creative Commons Attribution 4.0 International License, which permits use, sharing, adaptation, distribution and reproduction in any medium or format, as long as you give appropriate credit to the original author(s) and the source, provide a link to the Creative Commons licence, and indicate if changes were made. The images or other third party material in this article are included in the article's Creative Commons licence, unless indicated otherwise in a credit line to the material. If material is not included in the article's Creative Commons licence and your intended use is not permitted by statutory regulation or exceeds the permitted use, you will need to obtain permission directly from the copyright holder. To view a copy of this licence, visit http://creativecommons.org/licenses/by/4.0/.

\section{References}

1. Prisco D, Ageno W, Becattini C, D'Angelo A, Davì G, De Cristofaro R, Dentali F, Di Minno G, Falanga A, Gussoni G, Masotti L, Palareti G, Pignatelli P, Santi RM, Santilli F, Silingardi M, Tufano A, Violi F, SIMI (Italian Society of Internal Medicine), FADOI (Federation of Associations of Hospital Doctors on Internal Medicine), SISET (Italian Society for the Study of Haemostasis and Thrombosis) (2017) Italian intersociety consensus on DOAC use in internal medicine. Intern Emerg Med 12(3):387-406

2. Tosetto A, Testa S, Palareti G, Paoletti O, Nichele I, Catalano F, Morandini R, Di Paolo M, Tala M, Esteban P, Cora' F, Mannino S, Maroni A, Sessa M, Castaman G (2019) The effect of management models on thromboembolic and bleeding rates in anticoagulated patients: an ecological study. Intern Emerg Med 14(8):1307-1315

3. European Centre for Disease Prevention and Control (2020) Infection prevention and control for COVID-19 in healthcare settingsthird update. 31 March 2020. Stockholm, ECDC
4. Bikdeli B, Madhavan MV, Jimenez D, Chuich T, Dreyfus I, Driggin E, Nigoghossian C, Ageno W, Madjid M, Guo Y, Tang LV, Hu Y, Giri J, Cushman M, Quéré I, Dimakakos EP, Gibson CM, Lippi G, Favaloro EJ, Fareed J, Caprini JA, Tafur AJ, Burton JR, Francese DP, Wang EY, Falanga A, McLintock C, Hunt BJ, Spyropoulos AC, Barnes GD, Eikelboom JW, Weinberg I, Schulman S, Carrier M, Piazza G, Beckman JA, Steg PG, Stone GW, Rosenkranz S, Goldhaber SZ, Parikh SA, Monreal M, Krumholz HM, Konstantinides SV, Weitz JI, Lip GYH (2020) cardiovascular considerations for patients, health care workers, and health systems during the coronavirus disease 2019 (COVID-19) pandemic. JACC. https://doi.org/10.1016/j.jacc.2020.03.031

5. Testa S, Prandoni P, Paoletti O, Morandini R, Tala M, Dellanoce C, Giorgi-Pierfranceschi M, Betti M, Danzi GB, Pan A, Palareti G (2020) Direct oralanticoagulant plasma levels striking increase in severe COVID-19 respiratory syndrome patients treated with antiviral agents. The Cremona experience. J ThrombHaemost. https://doi.org/10.1111/jth.14871

6. Tang N, Bai H, Chen X, Gong J, Li D, Sun Z (2020) Anticoagulant treatment is associated with decreased mortality in severe coronavirus disease 2019 patients with coagulopathy. J Thromb Heamost. 18(5):1094-1099. https://doi.org/10.1111/jth.14817

7. Han H, Yang L, Liu R, Liu F, Wu KL, Li J, Liu XH, Zhu CL (2020) Prominent changes in blood coagulation of patients with SARS-CoV-2 infection. CCLM/FESCC. https://doi.org/10.1515/ cclm-2020-0188

8. Testa S, Paoletti O, Giorgi-Pierfranceschi M, Pan A (2020) Switch from oral anticoagulants to parenteral heparin in SARS-CoV-2 hospitalized patients. Intern Emerg Med. https://doi.org/10.1007/ s11739-020-02331-1

9. Schulman S, Parpia S, Stewart C, Rudd-Scott L, Julian JA, Levine M (2011) Warfarin dose assessment every 4 weeks versus every 12 weeks in patients with stable international normalized ratios: a randomized trial. Ann Intern Med 155:653-659

10. Barnes GD, Kong X, Cole D, Haymart B, Kline-Rogers E, Almany S, Dahu M, Ekola M, Kaatz S, Kozlowski J, Froehlich JB (2018) Extended international normalized ratio testing intervals for warfarin-treated patients. J Thromb Haemost 16(7):1307-1312

Publisher's Note Springer Nature remains neutral with regard to jurisdictional claims in published maps and institutional affiliations. 